\title{
Saudi Nursing Students Experience of Distance Learning (e-learning) During COVID-19 2020 Pandemic Outbreak at KSAU-HS
}

\author{
Najla A. Barnawi ${ }^{1,2}$, Angham Al-Mutair ${ }^{1,2}$, and Hind Al-Ghadeer ${ }^{1,2}$ \\ ${ }^{1}$ College of Nursing, KSAU-HS, Riyadh 14611, Saudi Arabia \\ ${ }^{2}$ King Abdullah International Medical Research Centre (KAIMRC), Ministry of National Guard Health \\ Affairs, Riyadh, Saudi Arabia
}

*Corresponding author: Najla A. Barnawi; barnawin@ksau-hs.edu.sa

Received 17 February 2021;

Accepted 08 March 2021;

Published 17 March 2021

\begin{abstract}
Objectives: This study aims to assess the experience of the full Distance Learning approach among nursing students during COVID-19 Outbreak at KSAU-HS in the three regions (Riyadh, Jeddah, and Al-Ahsa). The study covers the following objectives; measuring the students' level of satisfaction, perception, and interest in integrating Distance Learning, their learning needs accomplishments; and determine the association between the student's level of satisfaction, perception/interest in integrating Distance Learning, and learning needs accomplishments. Methods: A cross-sectional study was conducted among 800 nursing students in the CON campuses. The validated 5-Lickert scale DSLLA, was used to assess the student's demographical data, satisfaction, and learning achievements. The $\mathrm{r}$ values were calculated to examine the correlation between the students' satisfaction and other study variables. Results: The majority of the participants were satisfied $70.9 \%$ and $90 \%$ were toward integrating the e-learning and $89.4 \%$ reported that they meet their learning needs. There was a statistically significant relationship between the participants' satisfaction with learning styles $(\mathrm{r}=0.305, \mathrm{P}=0.000)$ and their learning needs achievements $(\mathrm{r}=.600, \mathrm{P}=0.000)$. Conclusion: Integrating the companied learning style is the best learning option to deliver the pedagogy process within the Nursing curricula; however, the full distance learning approach is an effective tool on delivering the pedagogy process mainly during COVID-19.
\end{abstract}

Keywords: Distance Learning, Nursing students, Attitude, Learning Achievements, Pedagogy process, Adult Learning

\section{Introduction}

The current global COVID-19 outbreak leads academic institutions to rely on the distance-learning approach to continue delivering the educational regime at various levels. There is a significant increase in utilizing such a learning approach in various settings during the last two decades worldwide ${ }^{[1-3]}$. Nationally, the Saudi Ministry of Education (MOE) in 2007 imposed the notion of Distance Learning to enhance the digital transformation in various educational programs. Integrating the Distance Learning and e-learning approach has a unique experience in the medical-based academic institutions considering the pedagogical aspects as it has an efficient, cohesive, and rigorous process ${ }^{[4]}$. The current pandemic precautionary plan makes the educational policymakers incorporate the complete Distance Learning approach with fully e-learningbased styles at medical-based academic institutions, including nursing programs.

Based on the WHO's (2015) proposal of integrating Distance Learning as a strategy to overcome the staff shortage in the healthcare and academic contexts, several international nursing academic-based programs integrated it mainly in clinical extend ${ }^{[5-}$

${ }^{7]}$. For instance, utilizing Facebook application as an e-learning tool improved the clinical skills confidences among undergraduate nursing students, enhanced the reflective learning and developed a collegial relationships ${ }^{[8]}$. Further, e-learning significantly increasing in the clinical knowledge score of 367 nursing students after conducting a virtual clinical (pre-simulated $=7.63$ vs. postsimulation=8.68; $p<0.01)^{[9]}$. Integrating a notion of e-simulation enhanced the knowledge and learning satisfaction rate of 427 nursing students compared to traditional teaching method ${ }^{[10]}$. Additionally, fifty-six nursing students reported a positive learning experience after participating in MicroSim virtual cases, which increased their knowledge and self-learning skills with an alpha coefficient of $0.85^{[11]}$. In addition to the satisfactory learning experiences, nighty nine nursing students reported a positive perception toward electronic-based resources compared to the traditional-class method because they were more feasible and reliable in terms of its content ${ }^{[12]}$. Considering the stressful 
circumstances that nursing students face throughout the current outbreak, it is essential to explore that notion in such unexpected conditions. Taking into consideration that there is a lack of national or international standardization of the Distance Learning and elearning method. Thus, nursing-academic institutions have variations in terms of the applicability and feasibility of Distance Learning and e-learning. It is relevant to assume that nursing students' satisfaction is varied and worthy of examination and investigation.

This study aims to assess the experience of the full Distance Learning approach and e-learning method among nursing students during COVID-19 Outbreak. The following objectives provided deeper insights into the study aim; which are measuring the students' level of satisfaction, perception, and interest in integrating Distance Learning and learning needs accomplishments; and determine the association between the student's level of satisfaction, perception/interest in integrating Distance Learning, and learning needs accomplishments.

\section{Materials and Methods}

\section{Study Area, Sample and Sampling}

This study involved the three nursing colleges affiliated with King Saud bin Abdulaziz University for Health Sciences (KSAU-HS), formally established in 2005. KSAU-HS has three campuses in Riyadh, Jeddah and Al-Ahsa. The study investigators created an online SurveyMonkey link, a cloud-based software founded in 1999 and went public in September 2018. The study focuses on Saudi nursing students who enrolled full-time in any CON campuses from all academic years, starting from the basic undergraduate nursing courses up to advanced master level. The intended students should read and speak English, have the necessary computer skills to navigate the Blackboard system tools, and access internet access to take the test. The investigators excluded the enrolled students who been dropout the program before the COVID-19 outbreak. During the Spring 2020 semester, each participant who was willing to participate in the study and met the study inclusion and exclusion criteria immediately accessed the online Survey link posted on the CONs websites and have to finish the self-administered questionnaire at the same perioed. The calculated sample size of 1000 nursing students is 706 nursing students, with a confidence level of $95 \%$ and a $2 \%$ margin of error. A convenience sampling recruited 790 students. Applying a group matching was demonstrated to sustain the contingency of qualification criteria and academic level in the three campuses. The participants' actual number was 751 after applying the exclusion criteria and removing the incomplete survey.

\section{Data Collection Methods, Study Instruments, \& Measurements} The demographic information was collected to address the age, academic-level, and computer skill variables. Due to the lack of the satisfaction scale of the full Distance approach and learning needs accomplishment, the investigators developed the Distance Learning, and Learning Needs Accomplishment Scale (DLLNAS) and piloted it among 375 students. The DLLNAS includes eight close-ended items; five items assess satisfaction and learning achievements, which are in a 5-Lickert scale. One item assesses the perceptional aspect of utilizing Distance Learning and includes four positives vs. four negative perceptions. That item has Net Promoter Scores (NPS) that illustrate the passive or emotional subjective data, which includes a 10-point rating scale and then classified into Detractors (0-6), Passives (7-8), and Promoters (910). Two items focus on integrating the Distance Learning approach in the nursing curricula. The tool Cronbach's alpha was (0.7), which indicated the reliability and the internal consistency of the scale. The investigators randomly selected 208 students with different demographics, educational, and professional backgrounds to pilot the tool. All the participants reported that the tool assessed their satisfaction regarding learning distance. Further, the authors who are experts in the academic field and distance and e-learning approaches reviewed the instrument's content validity.

\section{Data Management and Analysis Plan}

IBM SPSS (C) version 26 (IBM Corporation, 2019) was used to analyze descriptive and inferential statistics. Descriptive statistics of demographic factors, learning needs achievements, and Distance Learning experiences were collected for comparison purposes. Furthermore, it compares the mean differences against the study hypotheses at a $95 \%$ confidence interval to determine if the differences between these statistical values are statistically significant. The inferential statistics include calculating the $r$ values to examine the correlation between the satisfaction and other variables associated with Distance Learning.

\section{Results}

\section{Participants General Demographic Data}

A total of 751 female undergraduate and master students participated in this study. The undergraduate students represented the most extensive sample group (96.9\%) compared to the only 23 students in a master's program. Participants in advanced undergraduate academic (seventh and eighth) levels represented the most considerable portion of the study sample (44.5\%), followed by those who are in the middle academic (sixth level, $30.5 \%$ ). Only $24 \%$ represents students in the basic academic levels, including fourth and fifth level (Table 1). The later adolescence group represented the largest group (95.2\%), followed by the early adulthood group (4.5\%) and middle adulthood group (0.3\%, Table 1). $85.1 \%$ of the participants reported average computer skills, which implied that most of the participants qualified to master all the computer requirements for the learning process. However, only $14.9 \%$ of the study sample reported as a beginner or expert status (7.2\% and $7.7 \%$, respectively, Table 1$)$.

Students Satisfaction, Learning Needs Accomplishments, and Utilization of the Blackboard in Distance Learning

The majority of the students were satisfied $(70.9 \%)$, and they were more satisfied with interactive sessions $(60.3 \%)$, while only $11.5 \%$ reported some dissatisfying experiences of Distance Learning (Table 2). A $51.5 \%$ of the study participants were toward combining both traditional and Distance Learning styles (Table 3). The results also implied that the participants were slightly toward integrating the e-learning in theoretical courses $(89.75 \%)$ than the clinical courses (76.3\%). 89.4\% reported that they meet their learning needs, and $66.13 \%$ reported that the Blackboard software was useful, $32.55 \%$ reported it has a high quality in terms of the learning materials, and $24.74 \%$ reported it was reliable in delivering the learning content. Furthermore, the result indicates that $58 \%$ of the study participants were either promoters or passives regarding utilization of the Blackboard in the future Distance Learning (Table 4).

Relationships: Distance Learning, Students Satisfaction and Learning Achievements

There is a statistically significant relationships between the participants' satisfaction with all Distance Learning variables $(\mathrm{r}=0.305, \mathrm{P}=.000)$, integrating both learning styles $(\mathrm{r}=.199, \mathrm{P}=.000)$ 
vs, e-learning only $(\mathrm{r}=.171, \mathrm{p}=.000)$, and learning needs achievements $(r=.600, p=.000$ Table 5). There was significant relationship in students' satisfaction and learning achievements the interactive sessions $(r=.517$, and $r=.649$, respectively $\mathrm{P}=.000)$ compared to recording sessions $(\mathrm{r}=.415$, and $\mathrm{r}=.519$, respectively $\mathrm{P}=.000)$. There was a significant relationship in both satisfaction and learning achievements in theoretical-based courses ( $\mathrm{r}=.365$, and $\mathrm{r}=.416$, respectively $\mathrm{P}=.000$ ) and clinical-based courses as well $(\mathrm{r}=.216$, and $\mathrm{r}=.313$, respectively $\mathrm{P}=.000$, Table 5$)$.
Relationships: Demographical Data and Satisfaction and Learning Achievements

There is no statistically significant association of the age factor and computer skills on the satisfaction level neither in the learning achievements. However, there was a statistically significant relationship of the academic level in both the satisfaction and learning achievement $(\mathrm{r}=.161$, and $\mathrm{r}=.174$, respectively $\mathrm{P}=0.000)$. There is a statistically significant relationship of the utilization of the Blackboard in both the satisfaction and learning achievements $(\mathrm{r}=.476$, and $\mathrm{r}=.523$, respectively $\mathrm{P}=0.000$, Table 5).

Table 1: Frequency of General Demographic

\begin{tabular}{|c|c|c|c|c|c|c|c|}
\hline \multicolumn{8}{|c|}{ Students' Perception of Integrating Distance Learning in CONs in Nursing Curricula } \\
\hline & \multicolumn{2}{|c|}{ Theoretical courses } & \multicolumn{2}{|c|}{ Clinical courses } & \multicolumn{3}{|l|}{ Types } \\
\hline & $\mathbf{F}$ & $\%$ & $\mathbf{F}$ & $\%$ & & $\mathbf{F}$ & $\%$ \\
\hline Not interested $(0 \%-<10 \%)$ & 77 & 10.3 & 177 & 23.6 & Traditional & 220 & 29.4 \\
\hline Slightly interested $(10 \%-<25 \%)$ & 100 & 13.3 & 153 & 20.4 & E-learning & 142 & 19.0 \\
\hline Moderately Interested $(25 \%-<50 \%)$ & 213 & 28.4 & 254 & 33.9 & \multirow[t]{3}{*}{ Both } & \multirow[t]{3}{*}{387} & \multirow[t]{3}{*}{51.7} \\
\hline Very Interested $(50 \%-<75 \%)$ & 172 & 22.9 & 108 & 14.4 & & & \\
\hline Highly Interested (75\% - 100\%) & 189 & 25.2 & 58 & 7.7 & & & \\
\hline
\end{tabular}

Table 2: General Statistical Overview of the Students Satisfaction

\begin{tabular}{|c|c|c|c|c|c|}
\hline \multicolumn{6}{|c|}{ General Demographic Data } \\
\hline \multicolumn{6}{|c|}{ Students' Academic } \\
\hline Undergraduate Status and Level & $\mathbf{F}$ & $\%$ & Graduate Status and & $\mathbf{F}$ & $\%$ \\
\hline Level 4 & 81 & 11.13 & Level & 19 & 82.6 \\
\hline Level 5 & 96 & 13.2 & Level 1 & NA & NA \\
\hline Level 6 & 229 & 31.6 & Level 2 & NA & NA \\
\hline Level 7 & 128 & 17.7 & Level 3 & 4 & 17.4 \\
\hline Level 8 & 194 & 26.8 & Level 4 & & \\
\hline Total & 728 & 96.9 & Total & 23 & 3.1 \\
\hline Age Classification & $\mathbf{F}$ & $\%$ & Computer Skills & $\mathbf{F}$ & $\%$ \\
\hline Later adolescences & 715 & 95.2 & Beginner & 54 & 7.2 \\
\hline Early adulthood & 34 & 4.5 & Average & 639 & 85.1 \\
\hline Middle adulthood & 2 & .3 & Expert & 58 & 7.7 \\
\hline Total & 751 & 100 & Total & 751 & 100 \\
\hline
\end{tabular}

Table 3: General Statistical Overview of the Students Perception of Integrating Distance Learning in Nursing Curricula

\begin{tabular}{|l|l|l|l|l|l|l|}
\hline \multicolumn{9}{|c|}{ Students Satisfaction } \\
\hline & Overall & Interactive Sessions & \multicolumn{2}{l|}{ Recording Sessions } \\
\cline { 2 - 7 } & F & \% & F & \% & F & \% \\
\hline Very Dissatisfied & 26 & 3.5 & 17 & 2.3 & 14 & 1.9 \\
Dissatisfied & 60 & 8.0 & 69 & 9.2 & 66 & 8.8 \\
Neither dissatisfied nor Satisfied & 133 & 17.7 & 212 & 28.2 & 205 & 27.3 \\
Satisfied & 319 & 42.5 & 302 & 40.2 & 297 & 39.5 \\
Very Satisfied & 213 & 28.4 & 151 & 20.1 & 169 & 22.5 \\
\hline
\end{tabular}

Table 4: General Statistical Overview of the Students Learning Needs Accomplishments

\begin{tabular}{|l|l|l|}
\hline \multicolumn{2}{|c|}{ Learning Needs Accomplishment } \\
\hline \multicolumn{2}{|c|}{ Frequency } \\
\hline Not at all Well (0\%- less than 10\%) & 17 & 2.3 \\
Not so Well (10\% - less than 25\%) & 63 & 8.4 \\
Well (25\% - less than 50\%) & 226 & 30.1 \\
Very Well (50\% -less than 75\%) & 295 & 39.3 \\
Extremely Well (75\% - 100\%) & 150 & 20.0 \\
\hline Utilization of the Blackboard in Distance Learning & Frequency & $\%$ \\
\hline Students Opinions & 168 & 24.74 \\
\hline Reliable & 221 & 32.55 \\
High quality & 449 & 22.83 \\
Useful & 155 & 11.05 \\
Unique & 75 & 7.66 \\
Impractical & 52 & \\
Ineffective & \multicolumn{2}{|l|}{} \\
\hline
\end{tabular}




\begin{tabular}{|l|l|l|}
\hline $\begin{array}{l}\text { Poor quality } \\
\text { Unreliable }\end{array}$ & 56 & 8.25 \\
\hline \multicolumn{2}{|c|}{30} & 4.42 \\
\hline \multicolumn{2}{|c|}{ Recommendation for Future Use } \\
\hline Detractors (0-6) & Frequency & $\%$ \\
Passives (7-8) & 316 & 42.1 \\
Promoters (9-10) & 258 & 34.4 \\
Total & 177 & 23.6 \\
\hline
\end{tabular}

Table 5: Associations between the Students Satisfactions and Distance Learning

\begin{tabular}{|c|c|c|c|c|}
\hline \multicolumn{5}{|c|}{ Overall Satisfaction with the Distance Learning, } \\
\hline & Learning styles & Both Styles & e-learning Style Only & Learning Need Accomplishments \\
\hline Correlation & $.305 * *$ & $.199 * *$ & $.171 * *$ & $.600 * *$ \\
\hline Sig. (2-tailed) & .000 & .000 & .000 & .000 \\
\hline \multicolumn{5}{|c|}{ Satisfaction with e-learning Methods and Courses Types } \\
\hline e-learning & Interactive & Recording & Theoretical courses & Clinical courses \\
\hline Correlation & $.517 * *$ & $.415 * *$ & $.365 * *$ & $.216^{* *}$ \\
\hline Sig. (2-tailed) & .000 & .000 & .000 & .000 \\
\hline \multicolumn{5}{|c|}{ Learning Need Accomplishments with the Learning Methods and Courses Types } \\
\hline e-learning & Interactive & Recording & Theoretical courses & Clinical courses \\
\hline Correlation & $.649 * *$ & $.519 * *$ & $.416^{* *}$ & $.313 * *$ \\
\hline Sig. (2-tailed) & .000 & .000 & .000 & .000 \\
\hline \multicolumn{5}{|c|}{ Distance Learning Experiences Satisfaction with Participants Demographic Data } \\
\hline & Age & Computer Skills & $\begin{array}{l}\text { Students' Academic } \\
\text { Status and Level }\end{array}$ & $\begin{array}{l}\text { Utilization of the Blackboard in Distance } \\
\text { Learning }\end{array}$ \\
\hline Correlation & .044 & .051 & $.161 * *$ & $.476^{* *}$ \\
\hline Sig. (2-tailed) & .223 & .165 & .000 & .000 \\
\hline \multicolumn{5}{|c|}{ Distance Learning Needs Accomplishment with the Participants Demographic Data } \\
\hline & Age & Computer Skills & $\begin{array}{l}\text { Students' Academic } \\
\text { Status and Level }\end{array}$ & $\begin{array}{l}\text { Utilization of the Blackboard in Distance } \\
\text { Learning }\end{array}$ \\
\hline $\begin{array}{l}\text { Correlation } \\
\text { Sig. (2-tailed) }\end{array}$ & $\begin{array}{l}.059 \\
.108\end{array}$ & $\begin{array}{l}.036 \\
.321\end{array}$ & $\begin{array}{l}.174 * * \\
.000\end{array}$ & $\begin{array}{l}.523 * * \\
.000\end{array}$ \\
\hline
\end{tabular}

\section{Discussion}

The relationship between the participants' satisfaction with all variables implies that Distance Learning is a convenient learning method. Distance Learning approach enhances student-centered based, which is an essential element in motivating the students to achieve their learning needs ${ }^{[13]}$. Integrating combined -hybridlearning styles in the CON programs is the first option to successfully deliver the pedagogy process mainly during the COVID-19 for both undergraduate and master programs. The findings matched several study findings that acknowledged the importance of integrating the blended Distance Learning approach in achieving learning objectives, creating a safe and productive learning environment and enhancing ideas transformation ${ }^{[14-16]}$.

Both interactive and recording sessions have a strong association with the students' overall satisfaction and learning achievements. Nevertheless, the interactive sessions are a more favorable method. Such findings correspond with other studies that addressed the importance of interactive learning in enhancing students' comprehension and practical communication skills during the learning process [17-21]. Additionally, the interactive online sessions help the adult learners to take an active role in the learning process and enhance the socialization process, which impacts positively in their learning satisfaction ${ }^{[20-21]}$. Further, the ediscussion enriches the self-tracking of students' progress during distance learning ${ }^{[18,19]}$. Thus, it implies that the interactive session enforces the reflective-learning approach, which is essential in adult-learning within nursing programs.
However, recording sessions sustain the concept of the self-learning approach that allows the adult learner to autonomously select the learning aspects that require further improvement [22-24]. Several scholars reported that recording sessions enhance nursing students' awareness, mainly when acquiring new knowledge ${ }^{[22-23] .}$ Further, it activates cognitive and emotional learning, especially when considering the connection between touring, feedback, and technology utilization [14,22,25]. Therefore, recording sessions should be used as extra-tutorial resources in the nursing programs, considering that the students' learning needs achievement variations. Indeed, the learning needs achievements are accomplished more in the theoretical than clinical courses. Some scholars affirmed such assumption and highlighted that recording sessions is an effective supplementary tool that allows nursing students to use it as an alternative method in teaching clinical skills compared with other teaching strategies ${ }^{[22]}$.

There is a variation in the demographical data in association with the students' satisfaction with Distance Learning. For instance, there was no relationship between age and computer skills in terms of the students' satisfaction with Distance Learning. Such a result affirmed in other findings, which emphasized the absence of association between the age and the Distance Learning satisfaction $(\mathrm{F}=1.035, \mathrm{p}=.309){ }^{[26]}$. Further, the computer skills did not have any association in both Distance Learning and hybrid learning groups $\left(2.5(0.9)\right.$ and $2.1(0.8) \mathrm{P}=.14$, respectively) ${ }^{[27]}$. One of the justifications is that Distance Learning eventually enhancing the students' computer skills among adult learning, especially if there are clear instructions that serve the learning 
process ${ }^{[17,20]}$ Another opinion is that the young generation students are more technology-orientated, which allows them to utilize the computer skills to achieve their learning process requirements $[2,13,21]$.

The relationship between the academic level and satisfaction with Distance Learning and learning needs achievement implied that the senior nursing students are more satisfied with Distance Learning. The study findings affirmed the results of other studies, which claimed that senior students usually master their self-learning approach and more academic-technologybased orientation than their junior counterparts ${ }^{[14,17,26,27] .}$ Further, the relationship between the Blackboard tool's utilization with the satisfaction of Distance Learning, and learning needs achievement highlighted the importance of the accessibility and utilization of the course materials. Other scholars had the same view as they indicated a strong association between frequency of accessing the course materials online (t-test $=3.45, p=.002)^{[27]}$. Accordingly, examining Blackboard utilization is vital as it directly impacts students' satisfaction with Distance Learning.

Limited national literature and the lack of scientific resources that address the expansion of Distance Learning in higher education, mainly before the COVID-19 crisis presents, is one of the essential challenges of this study. There is a literature gap of pedagogy factors that enhance Distance Learning quality, mainly the assessment part, such as exams, and comprehended clinical competencies evaluation other than simulation technique. Further, this study is the first study that examines the nursing students' satisfaction, perception, and learning accomplishments, considering Distance Learning. Lacking randomization and including convenience sampling techniques that focus only on females' impact on the study generalizability. Therefore, there is a need to conduct further studies with a more representative sample drawn from all nursing programs within Saudi Arabia. Further, the study relied on the students' skills using audiovisual technology, which may vary from one student to another. All of these factors can create some bias in the responses. Furthermore, this study did not assess the negativity of solo Distance Learning on non-academic skills, such as building leadership skills and missing the benefit of learning in groups. The study did not examine the stress and anxiety levels associated with the COVID-19 pandemic.

\section{Conclusion}

The global alert response of the international COVID-19 insisted that national universities integrate the full Distance Learning approach. Fortunately, the KSAU-HS was one of the universities that provided prompt strategies to deliver the pedagogy process at medically-based academic programs during the present pandemic. Integrating the full approach Distance Learning was a new experience for all university students, including the nursing students. Therefore, this study explored that notion in terms of the nursing students' satisfaction and their learning need achievements. The majority of the participants were satisfied (70.9\%), and 51.5\% $(\mathrm{n}=387)$ were toward combined learning styles. Almost $90 \%$ were toward integrating the e-learning in theoretical courses, and $89.4 \%$ reported that they meet their learning needs. There was a statistically significant relationship between the participants' satisfaction with learning styles $(r=0.305, \mathrm{p}<0.01)$ and their learning needs achievements $(r=.600, p>0.01)$. Integrating the combined learning style is the best learning option to deliver the pedagogy process within the Nursing curricula in CONs at KSAUHS; however, the full Distance Learning approach is a useful tool on delivering the pedagogy process mainly during COVID-19.

\section{Recommendations}

There is a need to conduct studies with a higher scientific level of evidence that concern clinical and pedagogical aspects of Distance Learning in nursing programs within the Saudi context, such as randomized control trials (RCT) that aim to examine the impact of Distance Learning on the various variables associated with adultlearner. Further, mixed methods and qualitative research studies are highly recommended to assess students' level of satisfaction with limited required resources for Distance Learning. Moreover, there is a need for further literature that addresses ways other than the current simulation-clinical based learning styles. Since this study was the first scientific research that had only focused on female nursing students, further studies to be carried out should involve students from other colleges and faculties to investigate whether there are any similarities in the findings.

The expansion of advanced technology tools in the current education system in nursing and other healthcare-based academic program increases the urgency to intervene with different types of e-learning strategies [3,28]. For instance, some studies and technology organizations highlighted the impact of the virtual reality (VR), and Oculus Rift VR on the competent medical knowledge and clinical skills in medical and surgical fields ${ }^{[29-31]}$. Therefore, there is a need to pilot several studies aiming to utilize advanced VR technology such as Oculus Rift on educating healthcare professionals, including nursing students. The dissemination plan is directed to the academic institutions and publication journals. Local and national conferences and workshops should be conducted between the universities in Saudi Arabia.

Practical and accurate Distance Learning Standard Guidelines should be introduced in Academic-health curricula such as nursing and nursing-midwifery programs within and outside Saudi Arabia. It ensures the knowledge dissemination in the future at the medical and nursing profession. The knowledge transformation is also directed to all policymakers within the national Ministry of Higher Education. Reaching the key policymakers requires the knowledge to be disseminated by a collaborative effort between the administrative, academic, health managerial staff members, and EduTech group at KSAU-HS. Accordingly, the knowledge will be transferred easily and quickly with the facilitating of this network. To ensure understanding and knowledge transfer, conducting some presentations and seminars are highly recommended to ensure open discussions and face-toface interactions.

\section{Ethics approval and consent to participate}

Ethical approval of this study was obtained from the IRB of KAIMRC at KAMC with (Protocol Number: H-01-R-005) on May 6th, 2020. The participants received an electronic consent form through the management system of the KSAU-HS, which has a short description of the study and asks likely subjects about their willingness to participate in the study. They were asked to electronically sign the consent form, a requirement for them to access the pre-test and the post-test content. Their participation in this study was entirely voluntary, and they were free to discontinue the completion of the study at any time without penalty. No personal identifiers were collected or reported, and findings were reported as aggregate data. Risks in participating in this study are considered to be minimal. All the data saved in one computer, which required password access. In terms of human or animal tissue utilization was not applicable in this study. 


\section{List of abbreviations}

COVID-19: SARS-CoV2 virus

KSAU-HS: King Saud Bin Abdulaziz University for Health Sciences

CON: College of Nursing

MOE: Ministry of Education

WHO: World Health Organization

DLLNS: Distance Learning, and Learning Needs Accomplishment Scale

NPS: Net Promoter Scores

RCT: Randomized Control Trail

VR: Virtual Reality

EduTech: Educational Technology Department

IRB: Institutional Review Board

KAIMRC: King Abdullah International Medical Research Centre King Abdulaziz Medical City

\section{Data Availability}

The readers can access the data underlying the findings of the study, giving links to online repositories and providing deposition codes where applicable based on the journal rules and regulations.

\section{Conflicts of Interest}

The author(s) declare(s) that there is no conflict of interest regarding the publication of this paper.

\section{Funding Statement}

The publication fee of this article is funded by KAIMRC.

\section{CRediT Author Statement \& Authors Contributions}

Author/s testify that all persons designated as authors qualify for authorship and have checked the article for plagiarism. If plagiarism is detected, all authors will be held equally responsible and will bear the resulting sanctions imposed by the journal thereafter. accordingly, NB conceptualized and developed the study methodology, create the data entry and analysis software, wrote and reviewed the original paper. AAM prepared the research materials, and data interpretation process. HG provided a logistical support throughout the research project. All the authors have critically reviewed and approved the final draft and are responsible for the content and similarity index of the manuscript.

\section{Acknowledgments}

This research was supported by the King Abdullah International Medical Research Center and the College of Nursing Research Center. We would also like to show our gratitude to KSAU-HS authoritative people to facilitate the process of this study mainly Dr. Farida Habib and special thanks to the nursing students for sharing their pearls of wisdom with us during this research.

\section{Bibliography}

[1] Cant RP, Cooper SJ. Use of simulation-based learning in undergraduate nurse education: An umbrella systematic review. Nurse Education Today. 2017;49:63-71. doi:10.1016/j.nedt.2016.11.015
[2] Chang K-E, Chen Y-L, Lin H-Y, Sung Y-T. Effects of learning support in simulation-based physics learning. Computers \& Education. 2008;51(4):1486-1498. doi:10.1016/j.compedu.2008.01.007

[3] Lateef F. Simulation-based learning: Just like the real thing. Journal of Emergencies, Trauma, and Shock. 2010;3(4):348. doi:10.4103/0974-2700.70743

[4] eLearning for undergraduate health professional education. World Health Organization. https://www.who.int/hrh/documents/elearning_hwf/en/.

Published January 15, 2015. Accessed October 16, 2020.

[5] Rouleau G, Gagnon M-P, Côté J, et al. Effects of elearning in a continuing education context on nursing care: a review of systematic qualitative, quantitative and mixed studies reviews (protocol). BMJ Open. 2017;7(10). doi:10.1136/bmjopen-2017-018441

[6] Vaona A, Banzi R, Kwag K, et al. E-learning for health professionals ( Review ) Summary for findings for the main comparison. Cochrane Databse of Systematic Reviews.

2018;1:1-82. doi:doi.org/10.1002/14651858.CD011736.pub2.www.co chranelibrary.com

[7] Voutilainen A, Saaranen T, Sormunen M. Conventional vs. e-learning in nursing education: A systematic review and meta-analysis. Nurse Education Today. 2017;50:97103. doi:10.1016/j.nedt.2016.12.020

[8] Watson B, Cooke M, Walker R. Using Facebook to enhance commencing student confidence in clinical skill development: A phenomenological hermeneutic study. Nurse Education Today. 2016;2016(36):64-69. doi:10.1016/j.nedt.2015.07.019

[9] Bogossian FE, Cooper SJ, Cant R, Porter J, Forbes H. A trial of e-simulation of sudden patient deterioration (FIRST2ACT WEB ${ }^{\mathrm{TM}}$ ) on student learning. Nurse Education Today. 2015;35(10). doi:10.1016/j.nedt.2015.08.003

[10] Cooper S, Cant R, Bogossian F, Kinsman L, Bucknall T. Patient Deterioration Education: Evaluation of Face-toFace Simulation and e-Simulation Approaches. Clinical Simulation in Nursing. 2015;11(2):97-105. doi:10.1016/j.ecns.2014.10.010

[11] Heinrich C, Pennington RR, Kuiper R. Virtual Case Studies in the Classroom Improve Student Knowledge. Clinical Simulation in Nursing. 2012;8(8). doi:10.1016/j.ecns.2011.02.002

[12] Beers GW, Berry CG. Traditional versus electronic resources for students in clinical nursing courses: A pilot study. Online Journal of Nursing Informatics. 2015;19(1).

[13] Maksoud NFA. When Virtual Becomes Better than Real: Investigating the Impact of a Networking Simulation on Learning and Motivation. International Journal of Education and Practice. 2018;6(4):253-270. doi:10.18488/journal.61.2018.64.253.270

[14] Dziuban C, Graham CR, Moskal PD, Norberg A, Sicilia $\mathrm{N}$. Blended learning: the new normal and emerging technologies. International Journal of Educational Technology in Higher Education. 2018;15(1). doi:10.1186/s41239-017-0087-5

[15] Hayter M, Jackson D. Pre-registration undergraduate nurses and the COVID-19 pandemic: Students or workers? Journal of Clinical Nursing. 2020;29(1718):3115-3116. doi:10.1111/jocn.15317 
[16] Munshi F, Alsughayyer A, Alhaidar S, Alarfaj M. An online clinical examination for fellowship certification during the COVID-19 pandemic. Medical Education. 2020;54(10):954-955. doi:10.1111/medu.14267

[17] Ali WGM. Factors Affecting Nursing Student's Satisfaction with E- Learning Experience in King Khalid University, Saudi Arabia. International Journal of Learning and Development. 2012;2(2). doi:10.5296/ijld.v2i2.1666

[18] Bickle MC, Rucker RD, Burnsed KA. Online Learning: Examination of Attributes That Promote Student Satisfaction. Online Journal of Distance Learning Administration. 2019;22(1).

[19] Chan AW-K, Chair S-Y, Sit JW-H, Wong EM-L, Lee DT-F, Fung OW-M. Case-Based Web Learning Versus Face-to-Face Learning. Journal of Nursing Research. 2016;24(1):31-40. doi:10.1097/jnr.0000000000000104

[20] Opeyemi OZ, Adeyemi AA, Olajuwon TD, Oloruntosin ON, Oladeji BS. Perception of Nursing Students Towards Online Learning: A case Study of Lautech Open and Distance Learning Centre, Ogbomoso, Oyo State, Nigeria. Galore International Journal of Health Sciences and Research. 2019;4(4):23-30.

[21] Strong R. Investigating Students' Satisfaction with eLearning Courses: The Effect of Learning Environment and Social Presence. Journal of Agricultural Education. 2012;53(3):98-110. doi:10.5032/jae.2012.03098

[22] Ali NS, John B. Examining the Efficacy of Online SelfPaced Interactive Video-Recordings in Nursing Skill Competency Learning: Seeking Preliminary Evidence Through an Action Research. Medical Science Educator. 2019;29(2):463-473. doi:10.1007/s40670-019-00714-4

[23] Strand I, Gulbrandsen L, Sletteb $\varnothing$ Å, Nåden D. Digital recording as a teaching and learning method in the skills laboratory. Journal of Clinical Nursing. 2017;26(1718):2572-2582. doi:10.1111/jocn.13632
[24] Parilo DMW, Parsh B. Case Study: Student Perceptions of Video Streaming Nursing Class Sessions. Journal of Nursing Education. 2014;53(3):161-163. doi:10.3928/01484834-20140223-01

[25] Aeiad E, Meziane F. An adaptable and personalised Elearning system applied to computer science Programmes design. Education and Information Technologies. 2018;24(2):1485-1509. doi:10.1007/s10639-018-9836-x

[26] Chang K-Y, Toledo CA. Factors affecting student satisfaction in different learning deliveries. 2013:1-180.

[27] Sowan AK, Jenkins LS. Designing, delivering and evaluating a distance learning nursing course responsive to students needs. International Journal of Medical Informatics. 2013;82(6):553-564. doi:10.1016/j.ijmedinf.2013.02.004

[28] Rodríguez-Ardura I, Meseguer-Artola A. Presence in personalised e-learning - the impact of cognitive and emotional factors and the moderating role of gender. Behaviour \& Information Technology. 2016;35(11):1008-1018. doi:10.1080/0144929x.2016.1212093

[29] Diegmann P, Schmidt-Kraepelin M, Van den Eynden S, Basten D. 12th International Conference on Wirtschaftsinformatik. In: Benefits of Augmented Reality in Educational Environments - A Systematic Literature Review. Osnabrück, Germany: Osnabrück; 2015:15421556.

[30] Garcia-Sanchez S. Online Metacognitive Tasks For Efl Distance Learners. Turkish Online Journal of Distance Education. 2016. doi:10.17718/tojde.60563

[31] Kintu MJ, Zhu C, Kagambe E. Blended learning effectiveness: the relationship between student characteristics, design features and outcomes. International Journal of Educational Technology in Higher Education. 2017;14(1). doi:10.1186/s41239-0170043-4 